\title{
New technique for passage of endograft through problematic arch anatomy
}

\author{
Hitoshi Matsuda, MD, ${ }^{\mathrm{a}}$ Tetsuya Fukuda, MD, ${ }^{\mathrm{b}}$ Hiroshi Tanaka, MD, ${ }^{\mathrm{a}}$ and Kenji Minatoya, MD, ${ }^{\mathrm{a}}$ Osaka, \\ Japan
}

For successful thoracic endovascular aneurysm repair of lesions of the aortic arch, delivery of an endograft through the arch angulation is mandatory. Unfortunately, acute arch angulation or presence of an artificial graft, such as a replacement graft or an endoluminal stent-graft, can obstruct delivery of the device. This report introduces a new endovascular technique for delivering the endograft through a problematic arch anatomy.

\section{TECHNIQUE}

After the insertion of the stent-graft device with the guidance of a hard guidewire along the major curvature of the aortic arch, delivery of the device may become impossible at the orifice of the left subclavian artery, at a gap in the anastomosis between the artificial graft and the native aorta, or at an uneven or folded stent-graft. This difficulty can also be caused by a problem associated with the endograft device, such as an uneven taper between the tip of the device and the guidewire or a gap between the tip and the wrapping of the stent-graft.

When the stent-graft cannot be passed through the arch, the safety of endovascular maneuvers inside the ascending aorta, especially in terms of the absence of plaque inside, is confirmed and the snare of the Amplatz Goose Neck Snare Kit (ev3 Endovascular, Inc, Plymouth, Minn; arrows in Figure 1) is inserted from the femoral or iliac artery to the ascending aorta to snare the hard guidewire (Figure 1,B). The snare is then pulled back to the tip of the device (Figure 1,C), and the loop is tightened. The direction of the tip of the stent-graft is changed by retraction of the snare, and the stent-graft device is inserted (Figure 1,D). Because the stent-graft is pushed upward during the downward retraction, coordination through staggering is essential for the passage to succeed. Because of the similarity of the movement of the snare, we call this procedure the "lasso technique."

This technique has been used successfully for 7 patients. Three patients, including 1 patient with a right aortic arch, showed acute arch angulation. In 2 cases the endograft could

\footnotetext{
From the Departments of Cardiovascular Surgery ${ }^{\mathrm{a}}$ and Radiology, ${ }^{\mathrm{b}}$ National Cerebral and Cardiovascular Center, Osaka, Japan.

Disclosures: Authors have nothing to disclose with regard to commercial support.

Received for publication May 10, 2014; revisions received June 8, 2014; accepted for publication June 12, 2014; available ahead of print Aug 15, 2014.

Address for reprints: Hitoshi Matsuda, MD, Department of Cardiovascular Surgery, National Cerebral and Cardiovascular Center, 5-7-1 Fujishiro-dai, Suita, 5658565 Osaka, Japan (E-mail: hitmat@mist.ocn.ne.jp).

J Thorac Cardiovasc Surg 2014;148:3246-7

$0022-5223 / \$ 36.00$

Copyright (c) 2014 by The American Association for Thoracic Surgery

http://dx.doi.org/10.1016/j.jtcvs.2014.06.078
}

not be passed through the distal anastomosis of the artificial graft for total arch replacement, and the endograft had been previously placed in 2 others. The snare was inserted from the contralateral femoral artery in 5 patients and from the same sheath catheter for endografting in 2 patients. The stent-grafts could then be deployed at the position preoperatively planned for all patients. There were no instances of death or stroke related to this thoracic endovascular aneurysm repair.

\section{DISCUSSION}

When a fusiform aneurysm is located near or distal to the left subclavian artery, the arch shows deviation to the right and anterior side and the angulation of the arch is obtuse, and when the arch itself is dilated, delivery of the endograft inside the aneurysm cavity will not be restricted. As Malkawi and colleagues ${ }^{1}$ reported, the mean aortic arch angulation at the level of the left subclavian artery is around $120^{\circ}$; however, the angulation is acute when the aneurysm is saccular or is located at the top of the arch. In a patient with a right aortic arch, the angulation is usually very steep.

Despite the various refinements of the stent-graft device, a slightly uneven taper between the tip and guidewire, hardness of the stent-graft inside the sheath or the wrapping, or a small gap between the tip and stent-graft may make it difficult to slide the stent-graft against an uneven aortic inner surface such as can be found at the orifice of the left subclavian artery, at an anastomosis of the artificial graft, or at a previously placed stent-graft.

To control the direction of the stent-graft along the major curvature of the aortic arch, the snare is useful for changing or stabilizing the alignment of the hard guidewire. The snare can be inserted from the brachial artery, and use of a transseptal insertion has also been reported. ${ }^{2}$ To elucidate a similar issue, tortuous anatomy of thoracic aorta, a transseptal approach has been also reported. ${ }^{3,4}$ As both groins are usually prepared for puncture or subjected to a cutdown, however, the lasso technique that uses the femoral or iliac artery to insert the snare is the simplest.

Two key items need special attention for successful use of the lasso technique: (1) reconfirmation of the pathology of the ascending aorta to avoid embolism and (2) good coordination between manipulation of stent-graft and snare, which are pushed and pulled in opposite directions.

\section{CONCLUSIONS}

As well as being useful and safe, the lasso technique is the simplest method to facilitate passage of the endograft through a problematic arch anatomy. 


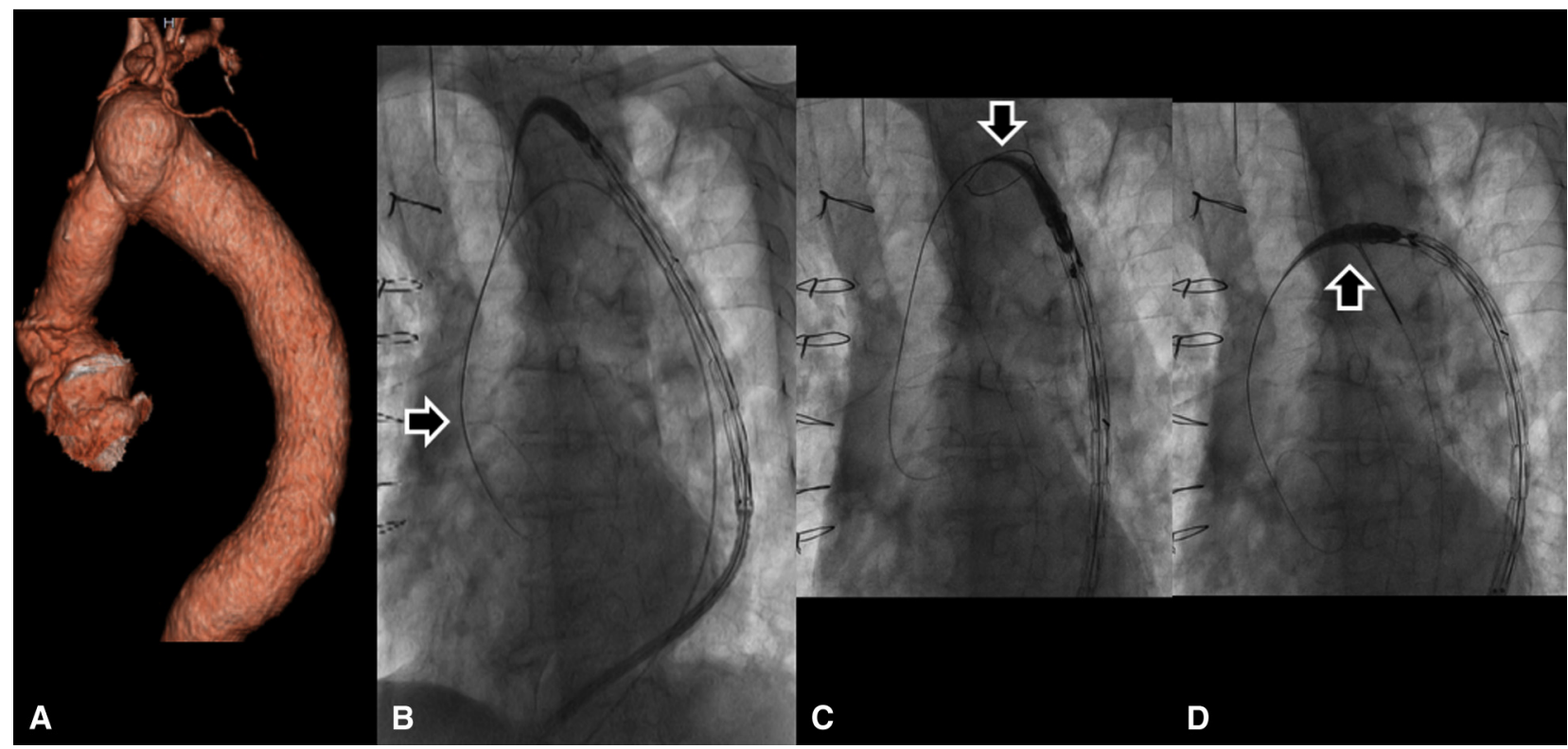

FIGURE 1. Lasso technique used in an 88-year-old man with a history of total arch replacement with a 24-mm multibranched polyester graft at the age of 70 years, abdominal aortic aneurysm replacement at 71 years, and replacement of the proximal ascending aorta with a $24-\mathrm{mm}$ polyester graft at 83 years. The aneurysm at the distal anastomosis of the arch graft developed at the top of the arch angulation. A, Left lateral projection of 3-dimensional computed tomography. B, C, and D, Fluoroscopic images during the lasso technique procedure. Arrows indicate snare.

\section{References}

1. Malkawi AH, Hinchliffe RJ, Yates M, Holt PJ, Loftus IM, Thompson MM. Morphology of aortic arch pathology: implications for endovascular repair. J Endovasc Ther. 2010;17:474-9.

2. Joseph G, Stephen E, Chacko S, Sen I, Joseph E. Transseptal ascending aortic access and snare-assisted pull down of the delivery system to facilitate stent-graft passage in the aortic arch during TEVAR. J Endovasc Ther. 2013;20:223-30.
3. Dorros G, Dorros AM, Planton S, O'Hair D, Zayed M. Transseptal guidewire stabilization facilitates stent-graft deployment for persistent proximal ascending aortic dissection. J Endovasc Ther. 2000;7:506-12.

4. Kölbel T, Rostock T, Larena-Avellaneda A, Treede H, Franzen O, Debus ES An externalized transseptal guidewire technique to facilitate guidewire stabilization and stent-graft passage in the aortic arch. J Endovasc Ther. 2010; 17:744-9.

\title{
Minimally invasive robotically assisted surgical resection of left atrial endocardial papillary fibroelastomas
}

\author{
Alina Hua, MBBS, ${ }^{a}$ Richard J. Shemin, MD, ${ }^{\mathrm{b}}$ Jeffrey P. Gordon, MD, ${ }^{\mathrm{c}}$ and Eric H. Yang, MD, ${ }^{\mathrm{c}}$ London, \\ United Kingdom, and Los Angeles, Calif
}

\footnotetext{
From the Department of Medicine, ${ }^{\mathrm{a}}$ Imperial College London, London, United Kingdom; the Division of Cardiothoracic Surgery, ${ }^{\mathrm{b}}$ Department of Surgery, and the Division of Cardiology, ${ }^{\mathrm{c}}$ Department of Medicine, University of California at Los Angeles, Los Angeles, Calif.

Disclosures: Authors have nothing to disclose with regard to commercial support. Received for publication June 16, 2014; accepted for publication June 29, 2014; available ahead of print Aug 29, 2014.

Address for reprints: Eric H. Yang, MD, Division of Cardiology, Department of Medicine, University of California at Los Angeles, 100 Medical Plaza Suite 630, Los Angeles, CA 90095 (E-mail: Datsunian@gmail.com).

J Thorac Cardiovasc Surg 2014;148:3247-9

$0022-5223 / \$ 36.00$

Copyright (c) 2014 by The American Association for Thoracic Surgery

http://dx.doi.org/10.1016/j.jtcvs.2014.06.100
}

Cardiac papillary fibroelastoma (PFE) is the third most common type of primary cardiac tumor after myxoma and fibroma. It is known to be the most common valvular tumor and accounts for $5 \%$ of all tumors of the heart, although nonvalvular endocardial origins have been reported. ${ }^{1}$ Although cardiac PFE is considered a benign tumor, surgical excision may be warranted because of its propensity for causing embolic events and hemodynamic complications.

\section{CLINICAL SUMMARY}

An 89-year-old woman with a history of hypertension and breast cancer was seen after a witnessed syncopal 